Article

\title{
Irradiation Facilities of the Takasaki Advanced Radiation Research Institute
}

\author{
Satoshi Kurashima *, Takahiro Satoh, Yuichi Saitoh and Watalu Yokota \\ Department of Advanced Radiation Technology, Takasaki Advanced Radiation Research Institute, \\ National Institutes for Quantum and Radiological Science and Technology, 1233 Watanuki, Takasaki, \\ Gunma 370-1292, Japan; satoh.takahiro@qst.go.jp (T.S.); saito.yuichi@qst.go.jp (Y.S.); \\ yokota.wataru@qst.go.jp (W.Y.) \\ * Correspondence: kurashima.satoshi@qst.go.jp; Tel.: +81-27-346-9636
}

Academic Editor: Klaus-Dieter Liss

Received: 11 January 2017; Accepted: 13 March 2017; Published: 20 March 2017

\begin{abstract}
The ion beam facility at the Takasaki Advanced Radiation Research Institute, the National Institutes for Quantum and Radiological Science and Technology, consists of a cyclotron and three electrostatic accelerators, and they are dedicated to studies of materials science and bio-technology. The paper reviews this unique accelerator complex in detail from the viewpoint of its configuration, accelerator specification, typical accelerator, or irradiation technologies and ion beam applications. The institute has also irradiation facilities for electron beams and ${ }^{60} \mathrm{Co}$ gamma-rays and has been leading research and development of radiation chemistry for industrial applications in Japan with the facilities since its establishment. The configuration and utilization of those facilities are outlined as well.
\end{abstract}

Keywords: ion beam; electron beam; gamma-ray; cyclotron; electrostatic accelerator; materials science; bio-technology; beam application; technical development

\section{Introduction}

The Takasaki Advanced Radiation Research Institute, former Takasaki Radiation Chemistry Research Establishment of Japan Atomic Energy Research Institute, was founded in 1963 to lead research and development (R\&D) of radiation chemistry for industrial applications in Japan. The irradiation facilities for electron beams and ${ }^{60} \mathrm{Co}$ gamma-rays have been operating for this purpose. The R\&D covered the synthesis and modification of polymers, immobilization techniques of bio-functional components, radiation vulcanization of natural rubber latex, removal of sulfur oxide and nitrogen oxides from flue gases, and studies of radiation effects on materials for space and nuclear power development. A number of resulting technologies became widespread, industrially. On the other hand, there was an observation that the application of ion beams was developing into an effective means for research not only in fundamental physics, but also in advanced technology in many other fields. Taking this background into account, an ion beam irradiation facility, Takasaki Ion Accelerators for Advanced Radiation Application (TIARA), was constructed in order to promote R\&D on materials science and bio-technology using ion beams and was fully in operation in 1993 [1,2]. TIARA is an accelerator complex consisting of an azimuthally-varying field (AVF) cyclotron and three electrostatic accelerators to cover wide ranges of ion species and beam energies to meet a variety of requirements from the R\&D subjects. The subjects include radiation-resistant materials in severe environments, space-radiation resistance of semiconductor devices, materials for nuclear fusion reactors, new functional materials, novel analytical technologies, mutation breeding, and so on. Those subjects utilize various types of beams or irradiation fields; for example, pulse beams at intervals longer than a few $\mu \mathrm{s}$, microbeams, and large-area uniform beams. Their typical beam time at the 
cyclotron is from less than one hour to a day, very short compared to usual physics experiments. In order to meet the experimental characteristics of materials science and bio-technology studies, TIARA is equipped with the large-area uniform beam irradiation devices with raster scanner for the cyclotron, and double- or triple-beam irradiation chambers using two or three different beams from electrostatic accelerators since its completion. A number of accelerator, irradiation, and analysis technologies have also been developed according to new requirements or progress of R\&D.

The operation time in fiscal 2015 is as follows: the cyclotron: $3089 \mathrm{~h}$; the tandem accelerator: $1976 \mathrm{~h}$; the single-ended accelerator: $2431 \mathrm{~h}$; the ion implanter: $1760 \mathrm{~h}$; the electron accelerator: $659 \mathrm{~h}$; and the gamma-ray irradiation facilities: $49,042 \mathrm{~h}$ (the total of eight irradiation rooms). Those facilities are made available to researchers in the National Institutes for Quantum and Radiological Science and Technology and other organizations for R\&D activities.

This paper describes, mainly, TIARA with accelerator specifications, major technologies of in-house development, and applications. The irradiation facilities of electron beam and the gamma-ray are also briefly outlined.

\section{Overview of the Facilities}

The configurations of TIARA, the electron irradiation facility, and the gamma-ray irradiation facilities are explained in the following subsections with pictures and illustrations.

\subsection{TIARA}

TIARA is comprised of the ion beam research building shown in Figure 1, the cyclotron building, and the multiple beam building. The total floor area is about $17,500 \mathrm{~m}^{2}$. Those buildings, and the accelerators, are drawn from a bird's-eye view in Figure 2. There are 4 accelerators of a K110 AVF cyclotron, a $3 \mathrm{MV}$ tandem accelerator, a $3 \mathrm{MV}$ single-ended accelerator, and a $400 \mathrm{kV}$ ion implanter, and they cover wide ranges of ion species and energies, from hydrogen to bismuth and from $20 \mathrm{keV}$ to $660 \mathrm{MeV}$, respectively, as shown in Figure 3.

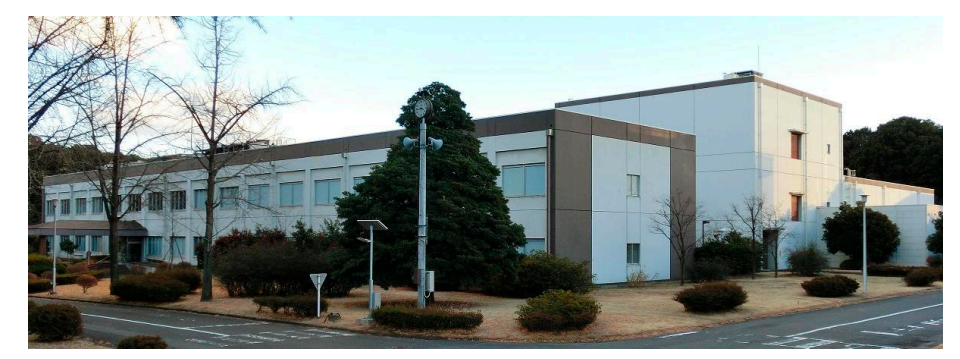

Figure 1. A picture of the ion beam research building of Takasaki Ion Accelerators for Advanced Radiation Application (TIARA).

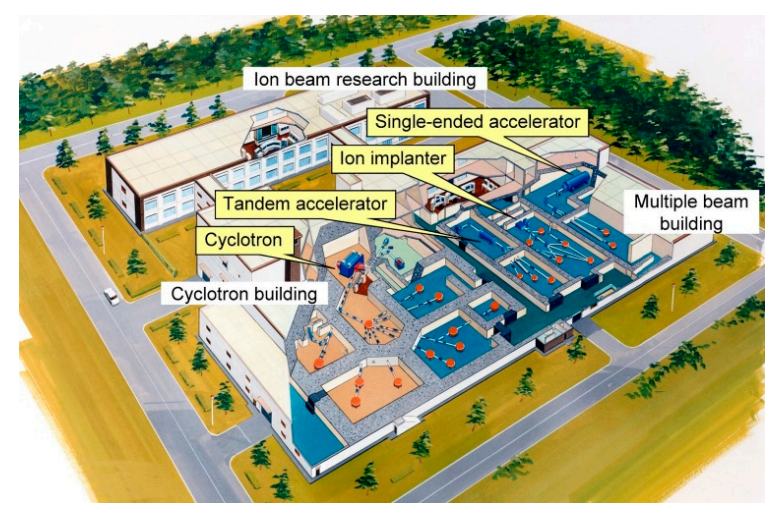

Figure 2. An illustration of TIARA buildings with the accelerators and the beam lines. 


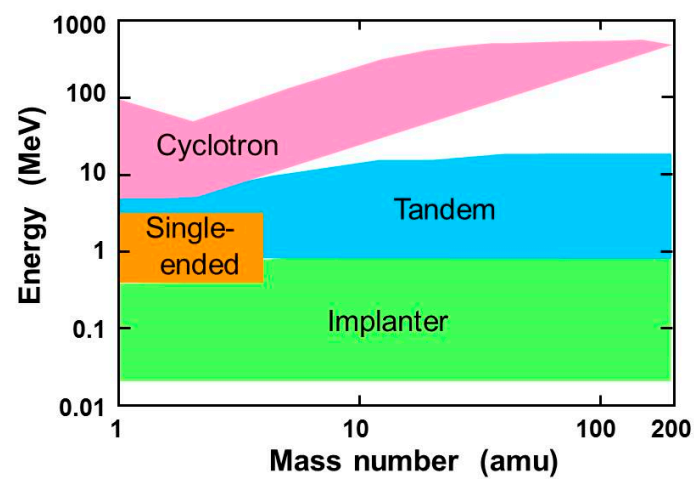

Figure 3. Range of ion species and beam energies covered by the four accelerators.

The cyclotron building contains four electron cyclotron resonance (ECR) ion sources, the cyclotron, and the beamlines equipped with irradiation ports at their ends. Ion beams produced by one of the ion sources in the basement are vertically injected into the cyclotron from its bottom. The accelerated beams are transported to one of ten horizontal beamlines distributed in five target rooms on the first floor and four vertical beamlines distributed in three target rooms in the basement.

The three electrostatic accelerators are installed in the multiple beam building and double- or triple-beam irradiation using the multiple accelerators are possible for research on such subjects as nuclear fusion reactor materials, as well as usual single-beam irradiation. There are four target rooms for ion beam irradiation, one for electron irradiation and a control room for three accelerators. The ion beam research building has a cyclotron control room, laboratories, building utilities, offices, etc.

The details of the system of the cyclotron and the electrostatic accelerator, and their beam application, are described in, and after, Section 3.

\subsection{Electron Beam Irradiation Facility}

The accelerator is of the Cockcroft-Walton type, installed in the second floor of the building shown in Figure 4. It consists of a high-voltage generator, a high-voltage terminal, an electron gun, and two acceleration tubes to accelerate electron beams in horizontal and vertical directions, respectively. The acceleration voltage ranges from $0.5 \mathrm{MV}$ to $2.0 \mathrm{MV}$, and the maximum beam intensity is $30 \mathrm{~mA}$. The electron beam is magnetically scanned linearly as wide as $120 \mathrm{~cm}$ and extracted from vacuum to the air through a $50 \mu \mathrm{m}$ thick window of titanium. Irradiation in a gaseous media and that with control of the target temperature are available. Studies of graft-polymerization for functional polymer fabrics, development of heat-resistant materials, creation of single-photon sources in wide bandgap semiconductors, etc., are carried out. Figure 5 shows the external view of the accelerator and the schematic drawing of its internal structure.

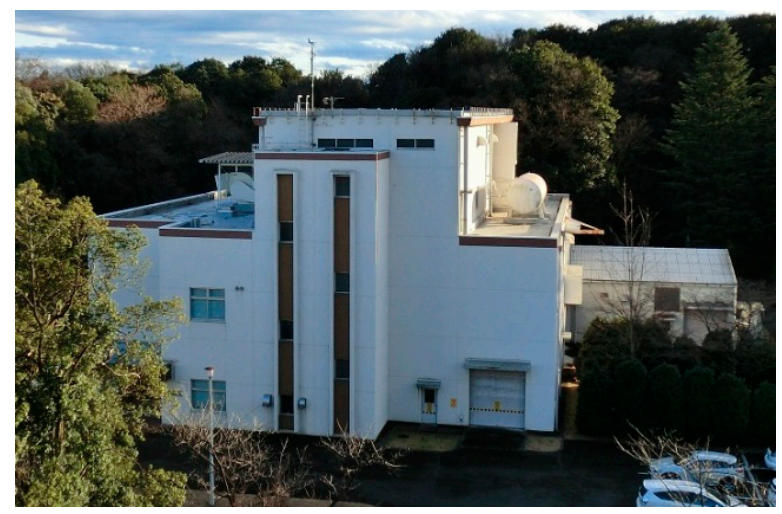

Figure 4. A picture of the building of the electron beam irradiation facility. 

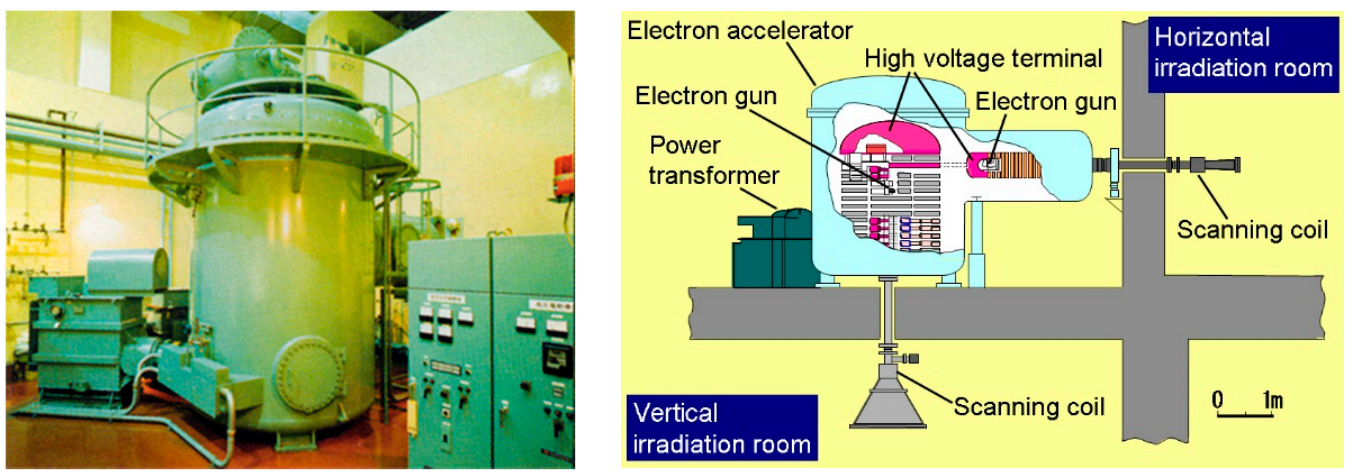

Figure 5. External view of the electron accelerator (left) and its internal structure and beam lines (right).

\subsection{Gamma-ray Irradiation Facilities}

The gamma-ray irradiation facilities are equipped with eight irradiation rooms in three buildings. Figure 6 shows external and internal views of one of the three buildings. The ${ }^{60} \mathrm{Co}$ sources are stored in water pools $4 \mathrm{~m}$ in depth, which are located under the irradiation rooms. The ${ }^{60} \mathrm{Co}$ sources are elevated upwards to the irradiation position in the air. The irradiation rooms are surrounded with $1.3 \mathrm{~m}$ thick heavy concrete walls for radiation shielding. The facilities cover a wide range of dose rates, from $10^{-1}$ to $10^{4} \mathrm{~Gy} / \mathrm{h}$. Irradiation in a gaseous media and temperature control of a target are available at those facilities, as well as the electron beam irradiation facility. Studies on graft-polymerization for functional polymer membranes, radiation resistance tests of materials and devices for use in nuclear facilities or space, improvement of polymer characteristics, functional material creation, radiation-induced bystander effects, and so on, are carried out.
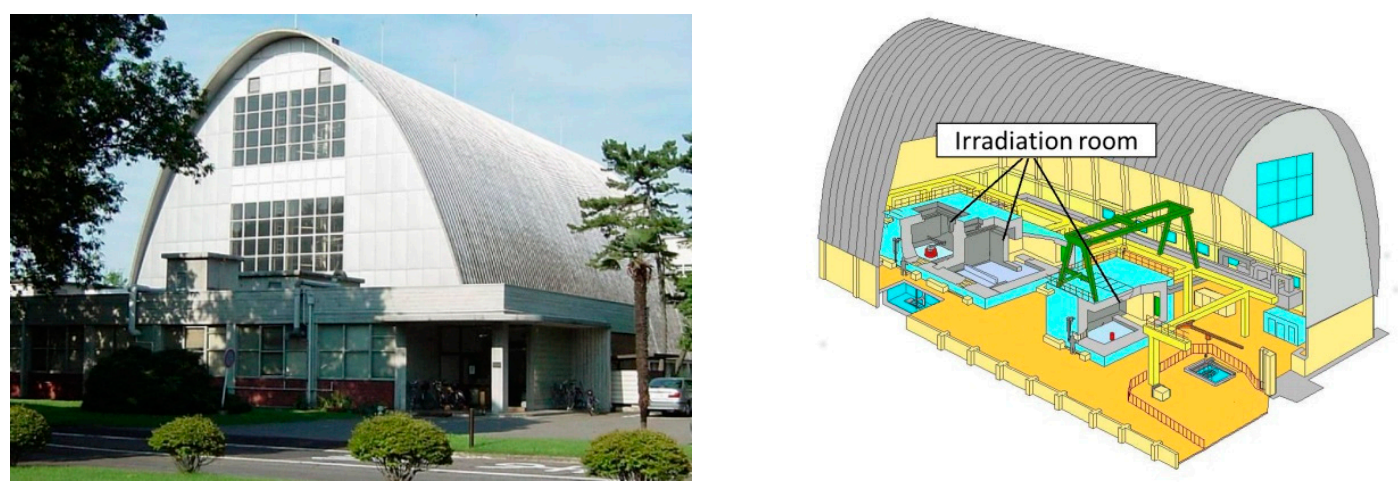

Figure 6. The external (left) and internal (right) views of one of the three buildings of the gamma-ray irradiation facilities.

\section{Cyclotron}

The specification and the characteristics of the cyclotron facility, including ion sources and beamlines, are described briefly in this section.

\subsection{AVF Cyclotron and Ion Sources}

The TIARA AVF cyclotron is of the model 930 of Sumitomo Heavy Industries, Ltd. (SHI, Niihama, Japan). Figure 7 shows an illustration of the cyclotron. The major components are two coaxial radio frequency $(\mathrm{RF})$ resonators and the normal conducting magnet. An ion beam produced by an external ion source is vertically injected into the cyclotron center through a spiral inflector electrode. Table 1 shows a specification of the cyclotron. The bending limit (K-value) and the focusing limit are $110 \mathrm{MeV}$ and $95 \mathrm{MeV}$, respectively. The acceleration harmonics of $h=1,2$ and 3, defined by the ratio of the 
acceleration frequency $f_{R F}$ to the orbital frequency of the ion $f_{i o n}$, are available and the cyclotron can provide various ion beams of $5 \mathrm{MeV}$ through $90 \mathrm{MeV} \mathrm{H}^{+}$and $2.5 \mathrm{MeV} / \mathrm{u}$ through $27 \mathrm{MeV} / \mathrm{u}$ for heavy-ions.

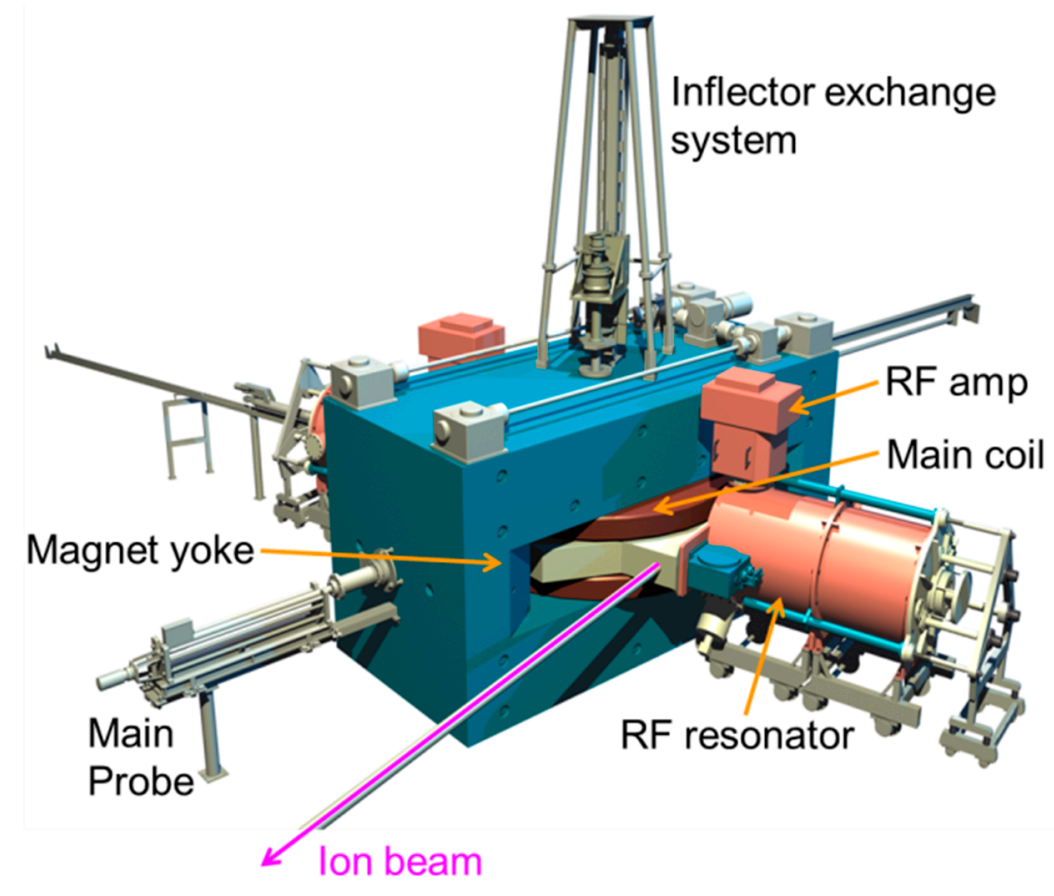

Figure 7. An illustration of the TIARA azimuthally-varying field (AVF) cyclotron. Size and weight of the magnet yoke are $5190 \times 2310 \times 2600 \mathrm{~mm}$ and 220 tons, respectively.

Table 1. Specification of the TIARA cyclotron.

\begin{tabular}{cc}
\hline Item & Specification \\
\hline Bending limit & $110 \mathrm{MeV}$ \\
Focusing limit & $95 \mathrm{MeV}$ \\
Max. average magnetic field & $1.64 \mathrm{~T}$ \\
Average extraction radius & $0.923 \mathrm{~m}$ \\
Number of sectors & 4 \\
Mass to charge ratio $(M / Q)$ & $1-6.5$ \\
Acceleration harmonics & $1,2,3$ \\
Acceleration frequency & $11-22 \mathrm{MHz}$ \\
Number of dees & 2 \\
Dee apan angle & $86 \mathrm{deg}$. \\
Max. dee voltage & $60 \mathrm{kV}$ \\
Max. RF power & $50 \mathrm{~kW}$ \\
Beam injection & Spiral inflector \\
Beam extraction & Electrostatic deflector \\
& Magnetic channel \\
& Gradient corrector \\
\hline
\end{tabular}

Four ECR ion sources listed in Table 2 are used to cover a wide range of ion species. The OCTOPUS ion source is mainly used for cocktail beam acceleration described later. The HYPERNANOGAN ion source (HECR) produces metal ions such as ${ }^{56} \mathrm{Fe}^{15+},{ }^{102} \mathrm{Ru}^{22+}$, and ${ }^{192} \mathrm{Os}^{30+}$ by the Metal Ions from VOlatile Compounds (MIVOC) method [3], as well as gaseous ions. The L-ECR ion source, developed at TIARA, can produce light ion beams very stably because of strict temperature regulation of the plasma chamber coolant [4]. The Nanogan ion source produces ions of helium or lighter elements. 
The cyclotron is equipped with ten horizontal beamlines and four vertical branch beamlines as shown in Figure 8. The vertical beamlines permit irradiation of unfixable targets, such as plant seeds and samples in a solution. The beamlines are categorized into two groups, one for light-ion (named $\mathrm{L}^{*}$ ) and the other for heavy-ion (named $\mathrm{H}^{*}$ ) irradiation. Light ion beams, such as $\mathrm{H}^{+}$and $\mathrm{D}^{+}$, are also available at the heavy-ion beamlines, but the beam intensity is regulated quite low compared to the light-ion beamlines because of the radiation shielding ability of the building.

Table 2. List of the electron cyclotron resonance (ECR) ion sources.

\begin{tabular}{ccccc}
\hline & $\begin{array}{c}\text { Microwave } \\
\text { (GHz) }\end{array}$ & Magnet & Use & Maker \\
\hline OCTOPUS & $6.4 / 14.3$ & Electrical & Cocktail beam & IBA* (Belgium) \\
HECR & 14.5 & Electrical & Heavy ions incl. metal & Pantechnik (France) \\
L-ECR & 12 & Parmanent & $\mathrm{H}^{+}$to oxgen & In-house \\
Nanogan & 10 & Parmanent & $\mathrm{H}^{+}, \mathrm{D}^{+}$, and helium & Pantechnik \\
\hline \multicolumn{5}{c}{ * Ion Beam Applications }
\end{tabular}

\subsection{Beamlines}

The ion sources are installed in the basement, as shown in Figure 8, and the ion beam produced by one of the ion sources is injected into the cyclotron from the underside. A set of perforated metal plates with opening ratios of $10^{-3}, 10^{-2}$, and $10^{-1}$ is installed in the injection line to easily reduce the ion beam intensity over ranges of $10^{-1}$ to $10^{-12}$ with a combination of multiple plates. A rectangular pulse voltage beam kicker, called the P-chopper, is placed in the vertical injection line, as shown in Figure 8. The P-chopper is used to inject a short duration beam about one cycle length of the acceleration frequency for single-pulse beam formation and to control the beam injection for single-ion hit irradiation using a microbeam. The details of the single-pulse, single-ion hit and the microbeam formation are described later.
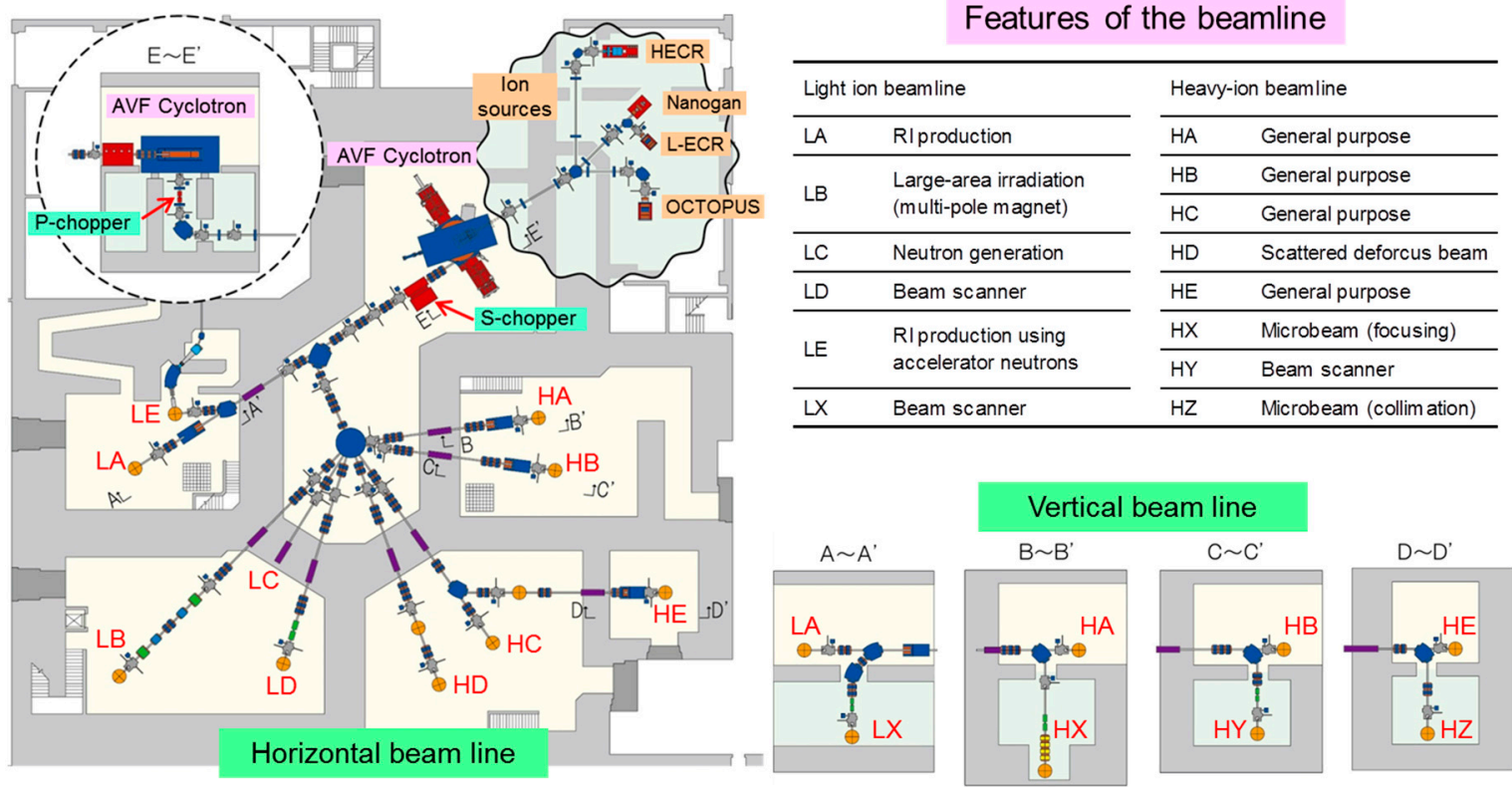

Figure 8. Layout of the ion sources, the cyclotron, and the beam transport lines, including ten horizontal and four vertical lines. 


\section{Cyclotron Technology Development}

The TIARA cyclotron was constructed to provide ion beams mainly for bio-technology and materials science, and a number of technologies necessary for those research fields are developed as described in the following subsections. In addition, a flat-top (FT) acceleration [5], beam phase bunching effect [6], and beam emittance-acceptance matching [7] have been developed.

\subsection{Magnetic Field Stabilization of the Cyclotron}

It is well known for many cyclotrons that beam intensity gradually decreases after the start of operation. Since the start of routine operation of the TIARA cyclotron in 1991, a rapid decrease of the beam intensity was often observed during several hours after the cyclotron magnet was excited. This phenomenon is caused by heat from the main coil, as follows: (1) The heat conducts to the surface of the magnet yoke; (2) The temperature of the magnet increases by a few degrees and the pole gap of the magnet is slightly enlarged by heat deformation; (3) The magnetic field strength of the cyclotron gradually decreased by the order of $10^{-4}$, as shown in Figure 9 (blue solid line). Frequent beam changes due to short beam times enhanced this phenomenon at TIARA.

To insulate the heat from the main coil, water-cooled copper plates were installed between the main coil and the facing surface of the magnet yoke [8]. The temperature of the cooling water is set between $22{ }^{\circ} \mathrm{C}$ and $25{ }^{\circ} \mathrm{C}$ by $0.1{ }^{\circ} \mathrm{C}$ as a function of the main coil current. To keep the magnet warm when not in operation, such as on weekends, the cooling water circulates at $28^{\circ} \mathrm{C}$. As a result, the magnetic field instability was remarkably improved as shown in Figure 9 (red solid line) for any main coil currents. The beam intensity has become satisfactorily stable. The magnetic field stabilization has led to the realization of single-pulse beam formation and microbeam formation.

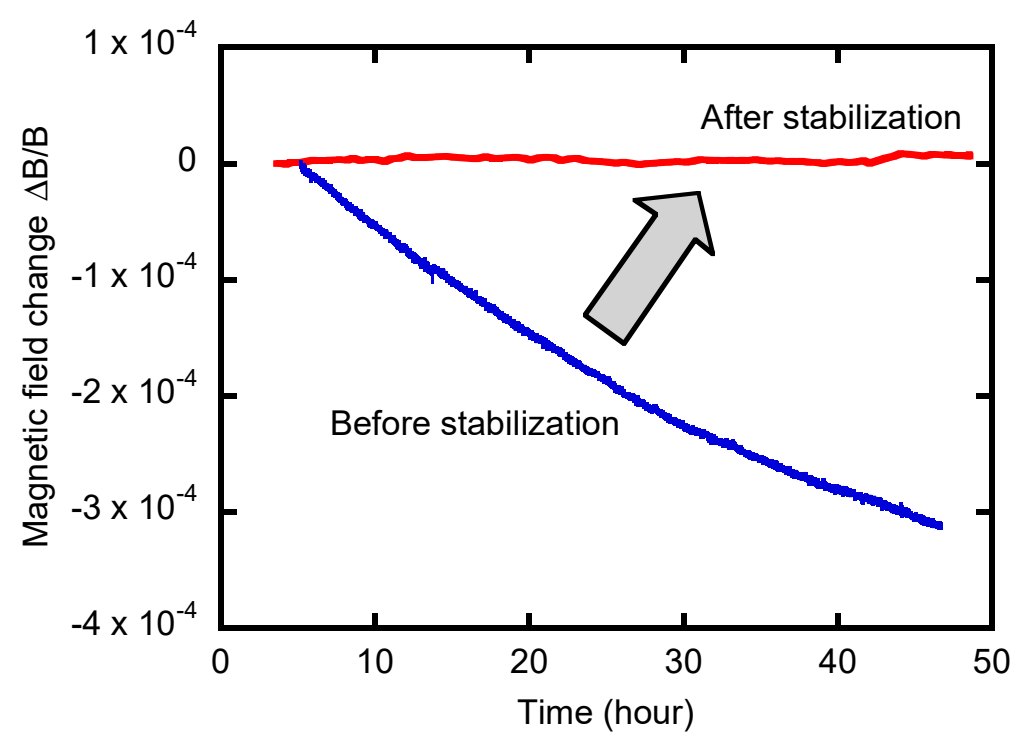

Figure 9. Comparison of the magnetic field change before and after stabilizing the magnet temperature of the cyclotron. A nuclear magnetic resonance (NMR) probe was used to precisely measure the magnetic field in the cyclotron.

\subsection{Single-Pulse Beam Formation}

The intervals of beam pulses extracted from the cyclotron are varied between 45.5 and $90.9 \mathrm{~ns}$ depending on the acceleration frequency ranging from 11 to $22 \mathrm{MHz}$. This period is too short for experiments, such as pulse radiolysis and time-of-flight (TOF) for measuring neutron energy generated by a ${ }^{7} \mathrm{Li}(\mathrm{p}, \mathrm{n})$ reaction. A single-pulse beam, with intervals over $1 \mu \mathrm{s}$, is required for those experiments. A chopping system, consisting of two types of high-voltage kickers, shown in Figure 8, are used to 
form the single-pulse beam [9]. The first kicker (P-chopper) installed in the injection line generates beam pulses with a repetition period over $4.2 \mu \mathrm{s}$ with a short duration of about one cycle length of the acceleration frequency. The beam pulses are injected into the cyclotron and accelerated forming beam bunches. An internal beam bunch is divided into several parts when being extracted by a deflector electrode due to radial spread of the beam bunch, which is called multi-turn extraction. The second kicker (S-chopper) in the high-energy beamline thins out needless beam pulses caused by multi-turn extraction and the single-pulse beam is formed as a result. The S-chopper generates high-voltage $\mathrm{RF}$ ranging from 1 to $3 \mathrm{MHz}$, and the reduction rate of the beam bunches is selectable from $1 / 7$ to 1/3. Standalone use of the S-chopper is available, as shown in Figure 10a. To form the single-pulse beam, it is indispensable to reduce and keep the number of multi-turn extraction less than 10 or so. The multi-turn extraction number is reduced by the restriction of a beam phase width and precise optimization of a particle acceleration phase [10], and is kept constant owing to highly-stabilized magnetic field. The single-pulse beam was formed as shown in Figure $10 \mathrm{~b}$. The $\mathrm{H}^{+}$single-pulse beams of $50 \mathrm{MeV}$ and $65 \mathrm{MeV}$ are used for TOF measurement experiments to evaluate quasi-monoenergetic neutron fields generated at the LC beamline shown in Figure 8 [11].
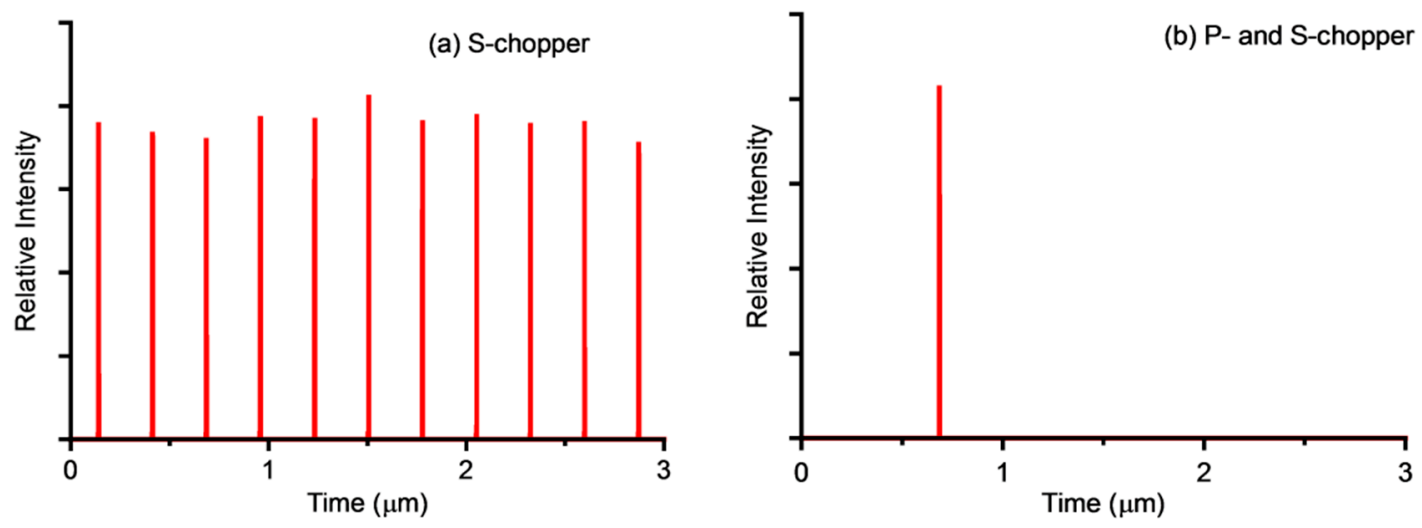

Figure 10. Beam pulse trains of the $65 \mathrm{MeV} \mathrm{H}^{+}$measured by a plastic scintillator. The intervals of the beam pulses were $43.7 \mathrm{~ns}\left(T_{R F}\right)$ without chopper operation. (a) S-chopper was used at a reduction ratio of $1 / 5(T=273 \mathrm{~ns})$; (b) P- and S-chopper were used simultaneously at repetition period of the P-chopper of $4.37 \mu \mathrm{s}\left(80 \times T_{R F}\right)$.

\subsection{Cocktail Beam Acceleration}

It is often required to widely change the linear energy transfer (LET) during a beam time, and it can be realized by quickly changing the ion species and/or energy. A cocktail beam acceleration technique [12] was developed for quick change of the ion species extracted from the cyclotron. In this technique, a cocktail of multiple species of ions having almost equal mass-to-charge ratio $(M / Q)$ is injected into the cyclotron, and an ion species separates from the others in the course of acceleration.

The principle of cyclotron acceleration is simply to set the acceleration frequency $f_{R F}$ at an integer multiple of the cyclotron frequency of the ion $f_{\text {ion }}$ (Equations (1) and (2)),

$$
\begin{gathered}
f_{R F}=h f_{\text {ion }} \\
f_{\text {ion }}=\frac{1}{2 \pi} \frac{e Q}{u M} B
\end{gathered}
$$

where $h$ is the acceleration harmonic, $e$ is the elementary electric charge, $Q$ is the charge state of the ion, $B$ is the magnetic field of the cyclotron, $u$ is the atomic mass unit, and $M$ is the mass of the ion in $u$. When the ion species with similar $M / Q$ are injected into the cyclotron simultaneously, the ion completely satisfying $f_{\text {ion }}=f_{R F} / h$ is accelerated, keeping its acceleration phase, and being extracted normally. The other ion species cannot be extracted from the cyclotron if their phase reaches the 
deceleration region, or the energy gain decreases considerably after hundreds of revolutions. The ion species can be changed quickly by adjusting $f_{R F}$ corresponding to the $M / Q$ difference.

The $M / Q$ resolution $R$ is defined by:

$$
R \equiv\left|\frac{(M / Q)}{\Delta(M / Q)}\right|=\left|\frac{f_{R F}}{\Delta f_{R F}}\right|
$$

and the value of the cyclotron is about 3300 . This means that the cyclotron can separate two ion species with $\Delta(M / Q) /(M / Q)$ larger than $3 \times 10^{-4}(=1 / 3300)$. Table 3 shows a list of the ion species with the $M / Q \approx 5$. These ion beams are frequently used at the HD beamline as described in Section 5.1. Other cocktail beams of $M / Q \approx 2,2.86,4,5.3$, and 6.4 are available.

Table 3. List of cocktail ions with $M / Q \approx 5$. Each of the $\Delta(M / Q) /(M / Q)$ is a difference from that of ${ }^{40} \mathrm{Ar}^{8+}$. LET and range in Si were calculated using the SRIM code [13].

\begin{tabular}{ccccccc}
\hline Ion & $M / Q$ & $\Delta(M / Q) /(M / Q)$ & $\begin{array}{c}\text { RF } \\
(\mathbf{M H z})\end{array}$ & $\begin{array}{c}\text { Energy } \\
(\mathbf{M e V} / \mathbf{A})\end{array}$ & $\begin{array}{c}\text { LET }^{*} \text { in Si } \\
\left(\mathbf{M e V} /\left(\mathbf{m g} / \mathbf{c m}^{2}\right)\right)\end{array}$ & $\begin{array}{c}\text { Range in } \\
\text { Si }(\mathbf{m m})\end{array}$ \\
\hline${ }^{15} \mathrm{~N}^{3+}$ & 4.9995 & $9.410 \times 10^{-4}$ & 13.867 & 3.751 & 3.45 & 52.7 \\
${ }^{20} \mathrm{Ne}^{4+}$ & 4.9976 & $5.606 \times 10^{-4}$ & 13.873 & 3.754 & 6.33 & 42.5 \\
${ }^{40} \mathrm{Ar}^{8+}$ & 4.9948 & 0 & 13.881 & 3.758 & 15.3 & 39.6 \\
${ }^{84} \mathrm{Kr}^{17+}$ & 4.9354 & $-1.189 \times 10^{-2}$ & 14.048 & 3.849 & 40.0 & 40.7 \\
${ }^{129} \mathrm{Xe}^{25+}$ & 5.1556 & $3.219 \times 10^{-2}$ & 13.447 & 3.527 & 69.2 & 38.4 \\
\hline \multicolumn{6}{c}{${ }^{*}$ Linear Energy Transfer }
\end{tabular}

\section{Experimental Apparatus and Application for the Cyclotron}

This section explains, in brief, two typical experimental apparatus for large-area uniform irradiation and microbeam irradiation.

\subsection{Large-Area Uniform Irradiation Apparatus}

There are three types of large-area uniform irradiation apparatus. One is raster scanning of a spot beam, another is a combination of uniformization by an octupole magnetic field and expansion by a quadrupole magnetic field, and the other is scattering by a gold foil.

Beam scanning systems using a set of dipole magnets (raster scanner) are installed at LD, LX, and HY beamlines to enlarge the irradiation area of the beam. Table 4 shows specification of the beam scanners. Seeds or leaves of a plant and biological cells put on a Petri dish are irradiated at the HY beamline in the air. Solar cells for space use and polymer films are irradiated at the LD beamline in a vacuum.

Table 4. Specification of the beam scanner. Irradiation uniformity in the scan area is less than $10 \%$.

\begin{tabular}{cccc}
\hline Beamline & Scan Area $\left(\mathbf{m m}^{\mathbf{2}}\right)$ & Frequency $\mathbf{X} \mathbf{( H z )}$ & Frequency $\mathbf{Y}(\mathbf{H z})$ \\
\hline LD (horizontal) & $100 \times 100$ & 50 & $0.25,0.5,1,2.5$ \\
LX (vertical) & $20 \times 20$ & 50 & $0.5,1,2.5,5$ \\
HY (vertical) & $50 \times 50$ & 50 & $0.5,1,2.5,5$ \\
\hline
\end{tabular}

At the LB beamline, a large-area beam formation method using the non-linear focusing force of multipole magnets was developed for efficient low-fluence irradiation without a beam scanner [14]. Two couples of octupole and sextupole magnets are installed near the end of the beamline. The octupole magnets are used for folding the transverse tail of the beam, and then for making the beam profile uniform. The sextupole magnets are used for correcting the asymmetry of the beam distribution. An example of the beam profile is shown in Figure 11. A large-area uniform beam over $100 \mathrm{~cm}^{2} \mathrm{can}$ be generated at uniformity below $10 \%$. Such unique beams are used for industrial applications, such as creation of nano-pore membranes. 
A gold foil with a thickness of 0.2 or $1 \mu \mathrm{m}$ is inserted in the HD line. An ion beam is scattered when passing through the foil, and is enlarged downstream. An irradiation area of about $50 \times 50 \mathrm{~mm}$, with a uniformity of less than $10 \%$, is formed. An electronic device is irradiated under operation in a large vacuum chamber at the HD beamline to investigate the single-event effect (SEE), which are errors in microelectronic circuits induced by a single energetic particle.

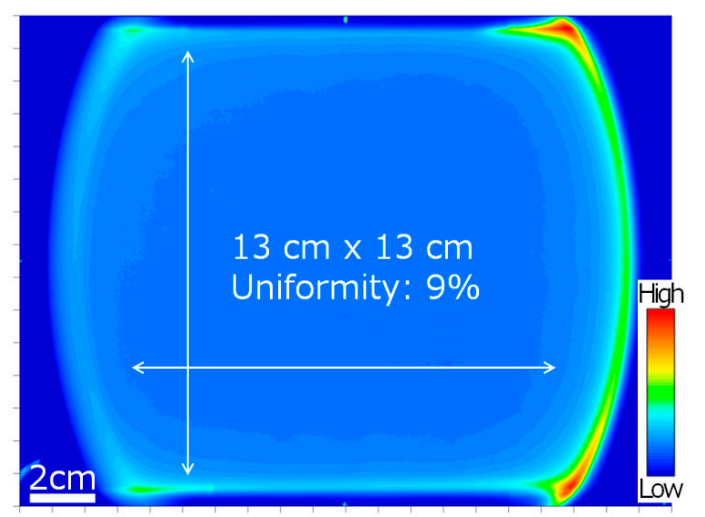

Figure 11. Two-dimensional relative intensity distributions obtained from the optical density distribution of a Gafchromic film HD-810 (Ashland Inc., Covington, KY, USA). The film was irradiated with the $385 \mathrm{MeV}^{40} \mathrm{Ar}$ beam formed using octupole magnets at the LB beamline.

\subsection{Microbeam Irradiation Apparatus}

A microbeam is generally described as an ion beam having the energy of over $1 \mathrm{MeV}$ and a diameter smaller than $10 \mu \mathrm{m}$. Two kinds of microbeam formation, collimation and magnet-focusing, are available at the TIARA cyclotron.

The collimated microbeam is formed by a pair of micro-collimators. Spot size of the microbeam is restricted due to the fabrication limit of the collimator and scattered ions at the edge of the collimator. For example, the minimum collimator size used for a $220 \mathrm{MeV}^{12} \mathrm{C}^{5+}$ beam is $20 \mu \mathrm{m}$. A target point is adjusted by moving a mechanical sample stage. Single-ion hit, which means irradiating a target point with ions one by one, is available by thinning the beam out using the P-chopper. Heavy-ion microbeam irradiation to living cells or small organisms in the air is carried out for elucidation of cellular radiation response at the HZ beamline [15].

To form a microbeam with a spot size of about $1 \mu \mathrm{m}$ with fewer scattered ions, a microbeam formation system using focusing magnets is installed in another vertical beamline (HX beamline) [16]. The system consists of quadruplet quadrupole magnets, microslits, divergence angle defining slits, and so on. Magnification factors of the focusing system for $X$ and $Y$ directions are, equally, $1 / 5$. The basis of the system to form the microbeam is similar to that of the electrostatic accelerators described in Section 7. An FT acceleration system using the fifth-harmonic frequency voltage of the acceleration frequency was developed to reduce the beam energy spread $\Delta \mathrm{E} / \mathrm{E}$ to the order of $10^{-4}$, which is necessary to decrease chromatic aberrations in the focusing magnet. As a result, a $260 \mathrm{MeV}{ }^{20} \mathrm{Ne}^{7+}$ beam was focused to $0.7 \mu \mathrm{m}$ in vacuum.

In the case of microbeam irradiation in the air, the beam size is larger because of scattering in the vacuum window and the atmosphere layers. For example, the $260 \mathrm{MeV}^{20} \mathrm{Ne}^{7+}$ beam is enlarged by about $2 \mu \mathrm{m}$ at a distance of $1 \mathrm{~mm}$ from the vacuum window made of $\mathrm{Si}_{3} \mathrm{~N}_{4}$ with a thickness of $200 \mathrm{~nm}$. Figure 12 shows a pit distribution made by single-ion hit irradiation to $5 \times 5$ points with $20 \mu \mathrm{m}$ pitch with the $260 \mathrm{MeV}^{20} \mathrm{Ne}^{7+}$ beam on a CR-39 solid-state nuclear track detector. The average targeting accuracy in the air was estimated to be about $3.5 \mu \mathrm{m}$ by analyzing the displacement of the pits from the target points. The beam spot size of several micrometers is small enough to irradiate an individual living cell. In addition, microbeams of the $220 \mathrm{MeV}^{12} \mathrm{C}^{5+}$ and $320 \mathrm{MeV}^{12} \mathrm{C}^{6+}$ beams with this spot 
size is available at the HX beamline in the air. The cocktail beam acceleration technique is applied to quickly change the ion species of the microbeam within $30 \mathrm{~min}$ while it takes about $8 \mathrm{~h}$ to form the microbeam in the usual way [17].

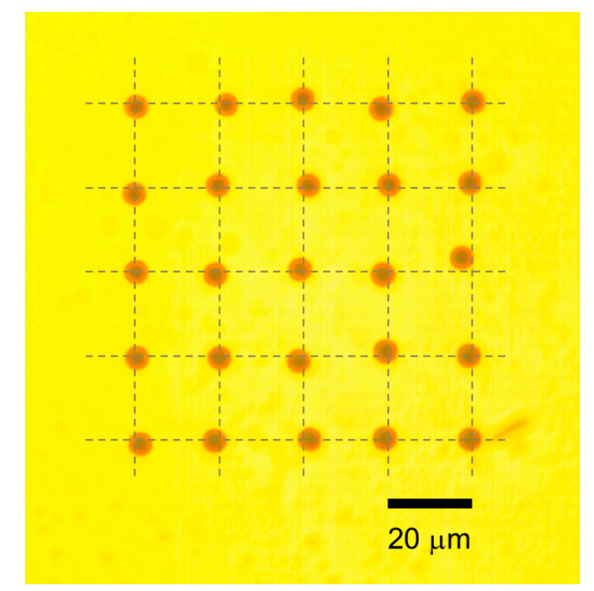

Figure 12. Photomicrograph of the CR-39 detector etched by a solution after $5 \times 5$ single-ion hits of the $260 \mathrm{MeV}{ }^{20} \mathrm{Ne}^{7+}$ without flat-top (FT) acceleration. The CR-39 was placed in the air at a distance of $1 \mathrm{~mm}$ from the vacuum window. The intersections of broken lines show the target points.

\section{Electrostatic Accelerators}

Three electrostatic accelerators are placed in the multiple beam irradiation building. Twelve irradiation apparatus are installed, including two microbeam apparatus connected to the tandem and the single-ended accelerators, two dual-beam irradiation chambers, and a triple-beam irradiation chamber. This section describes the outlines of the accelerators and the major apparatuses.

\subsection{Three Electrostatic Acclerators and Their Ion Sources}

The pelletron type $3 \mathrm{MV}$ tandem accelerator (9SDH-2, Figure 13a: National Electrostatics Corporation (NEC, Middleton, WI, USA)), equipped with two Cs sputter negative ion sources (SNICS II: NEC) and a charge exchange type RF negative ion source, provides ion beams, including cluster ion beams, in an energy range from $0.8 \mathrm{MeV}$ to $20 \mathrm{MeV}$. Negative ions produced with each ion source are injected into the tandem accelerator and accelerated toward the high voltage terminal in the middle of the accelerator vessel. The negative ions are stripped to positive ions upon colliding with the stripper gas in the charge exchange chamber, and the positive ones are reaccelerated toward the ground potential. A stripper gas of nitrogen generally used in a tandem accelerator is changed to that of helium when cluster ions are accelerated because the beam intensity of intact positive cluster ions increases [18]. A high-intensity $\mathrm{C}_{60}$ ion beam of a hundred pico-ampere level at an energy of $6 \mathrm{MeV}$ can be available using a helium stripper gas and is mainly supplied to develop a highly sensitive surface analysis by means of time of flight mass spectrometry. All ions that form a stable negative ion, including cluster ions such as $\mathrm{C}_{n}(n=2$ to 10$)$ and $\mathrm{Au}_{n}(n=2$ to 4$)$ [19] can be produced by the SNICS II, while negative $\mathrm{C}_{60}$ ions are produced with an electron attachment method originally developed at TIARA [20]. The charge exchange type RF ion source is used exclusively for production of unstable negative helium ions.

The principle of the negative ion production is briefly mentioned below, and the details are written elsewhere [21,22]. A negative ion other than helium is obtained by sputtering a surface of a cathode composed of materials to be ionized with Cs positive ions, via surface ionization by a Cs ionizer, which is a conical shaped tungsten heater. The cathode is covered with less than one monolayer of cesium atoms to increase production efficiency of the aimed negative ion. For generating $\mathrm{C}_{60}$ negative ions, the sputter cathode rod is replaced with a micro-oven rod, which is mechanically compatible with 
the sputter cathode rod, filled with $\mathrm{C}_{60}$ powder, so that the rod can be replaced easily [20]. A vaporized $\mathrm{C}_{60}$ molecule by the oven catches a thermal electron from the $\mathrm{Cs}$ ionizer and becomes a negative ion without Cs sputtering. The ionizer is used for an electron source in this method. In the charge exchange type $\mathrm{RF}$ ion source, positive helium ions produced by RF discharge are injected into a rubidium $(\mathrm{Rb})$ vapor cell, catches one electron from a $\mathrm{Rb}$ atom, then becomes an excited neutral atom, and finally becomes negative by gaining an additional electron through the second collision with $\mathrm{Rb}$.

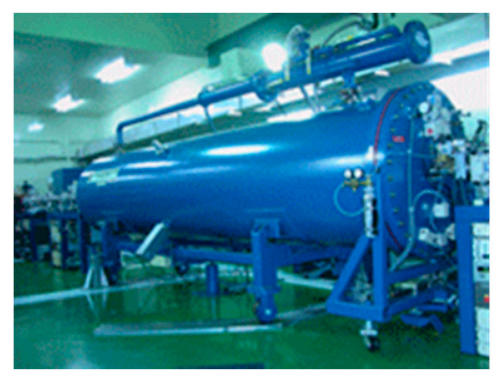

(a)

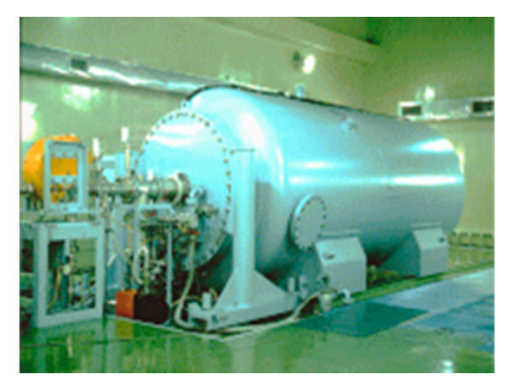

(b)

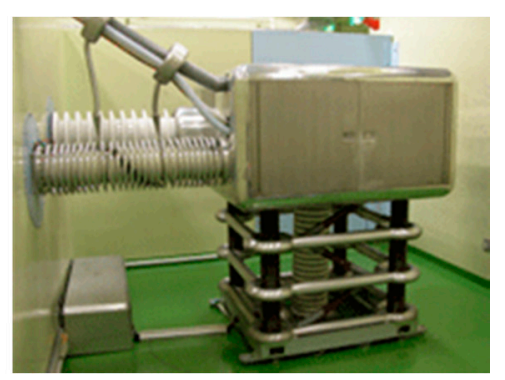

(c)

Figure 13. Three electrostatic accelerators at TIARA. (a) 3 MV tandem accelerator; (b) 3 MV single-ended accelerator; (c) $400 \mathrm{kV}$ Ion implanter.

The 3 MV single-ended accelerator (NC3000B, Figure 13b: Nissin High Voltage Co. (NHV, Kyoto, Japan)) with a balanced Schenkel-type DC power supply shown in Figure 13 has an extremely high voltage stability of $\pm 1 \times 10^{-5}$ for microbeam formation. The accelerator provides beams of $\mathrm{H}^{+}, \mathrm{D}^{+}$, $\mathrm{He}^{+}$, and $\mathrm{e}^{-}$in an energy range from $0.4 \mathrm{MeV}$ to $3 \mathrm{MeV}$. When electrons are accelerated, directions of all diodes in the DC power supply are reversed. A brief explanation of the accelerator is given in the following (see [2] for details). The Schenkel DC power supply is separated physically from the accelerating section in the pressure vessel to reduce the voltage ripple caused by the mechanical noise from a motor generator. Precision voltage measuring resistors are mounted along the central axis of the high-voltage generator to control the voltage drift. The voltage ripple is monitored with a capacitor-type ripple measuring circuit placed in parallel with the acceleration tube. An RF ion source with three gas bottles of hydrogen, helium, and deuteron is mounted in a high-voltage terminal. The electron beam is extracted from the hydrogen plasma generated with the RF ion source.

The $400 \mathrm{kV}$ ion implanter (NH-40SR, Figure 13c: Nissin Electrics Co. (NE, Kyoto, Japan)) of the Cockcroft-Walton type provides beams of $\mathrm{H}^{+}$to $\mathrm{Bi}^{+}$in an energy range from $10 \mathrm{keV}$ to $400 \mathrm{keV}$ by means of a Freeman-type ion source mounted in the high-voltage terminal. Heavy ion beams at energies up to several $\mathrm{MeV}$ can be obtained by replacing the ion source to an all permanent magnet type compact ECR ion source developed at TIARA [23]. Specifications of the accelerators are summarized in Table 5.

Table 5. Specifications of the electrostatic accelerators.

\begin{tabular}{|c|c|c|c|}
\hline Accelerator & Tandem & Single-Ended & Ion Implanter \\
\hline Model (maker) & 9SDH-2 (NEC) & NC3000B (NHV) & NH-40SR (NE) \\
\hline Charging system & Pelletron chain & Balanced-Schenkel & Cockcroft-Walton \\
\hline Acceleration voltage (MV) & $0.4-3.0$ & $0.4-3.0$ & $0.01-0.4$ \\
\hline Ion source & $\begin{array}{l}\text { Cs sputter type } \\
\text {. Charge exchange type }\end{array}$ & RF type & $\begin{array}{l}\text { - Freeman type } \\
\text { - All parmanent magnet type ECR }\end{array}$ \\
\hline Typical beam current & $\begin{array}{l}\mathrm{C}^{3+} 12 \mathrm{MeV}: 10 \mathrm{e} \mu \mathrm{A} \\
\mathrm{Ni}^{4+} 15 \mathrm{MeV}: 4 \mathrm{e} \mu \mathrm{A} \\
\mathrm{Au}^{3+} 12 \mathrm{MeV}: 12 \mathrm{e} \mu \mathrm{A} \\
\mathrm{C}_{60}{ }^{1+} 6 \mathrm{MeV}: 30 \mathrm{epA}\end{array}$ & $\begin{array}{l}\mathrm{H}^{+} 3 \mathrm{MeV}: 300 \text { е } \mu \mathrm{A} \\
\mathrm{He}^{+} 3 \mathrm{MeV}: 200 \text { енA } \\
\mathrm{e}^{-} 3 \mathrm{MeV}: 100 \text { е } \mu \mathrm{A}\end{array}$ & $\begin{array}{l}\mathrm{P}^{1+} 380 \mathrm{keV}: 100 \mathrm{e} \mu \mathrm{A} \\
\mathrm{Ag}^{1+} 380 \mathrm{keV}: 20 \mathrm{e} \mu \mathrm{A} \\
\mathrm{C}_{60}{ }^{1+} 360 \mathrm{keV}: 100 \mathrm{enA} \\
\mathrm{Ar}^{3+} 1000 \mathrm{keV}: 17 \mathrm{e} \mu \mathrm{A}\end{array}$ \\
\hline
\end{tabular}




\subsection{Typical Beam Irradiation Apparatus}

Two dual-beam analysis systems are placed in the No. 2 target room. They are designed for in situ or successive analysis of materials surface modified by ion beams. The one connected to the tandem accelerator and the implanter beamlines shown in Figure 14a allows the analysis of material surfaces by nuclear reaction analysis (NRA) or elastic recoil detection analysis (ERDA) using heavy ions from the tandem accelerator simultaneously with changing a material's properties by implantation of a variety of ions from the implanter. The other, connected with the single-ended accelerator and the implanter shown in Figure 14c, can be used for Rutherford backscattering (RBS) by means of light ions from the single-ended accelerator simultaneously with changing a material's properties by ion implantation.

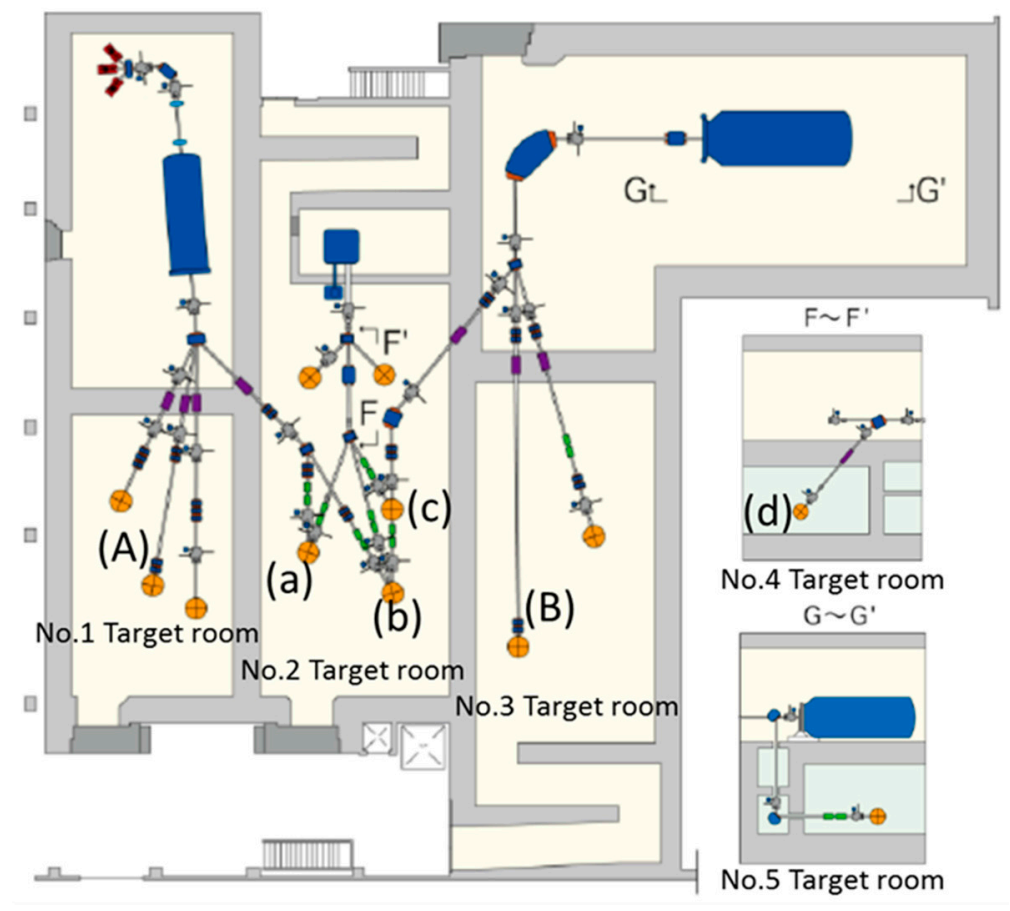

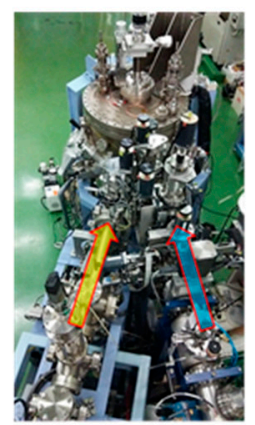

(a)Dual beam (Tandem and Implanter)

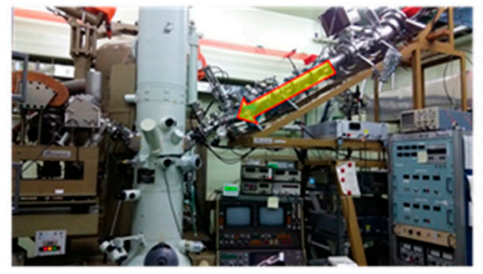

(d) Integrated $400 \mathrm{kV}$ analytical electron microscope

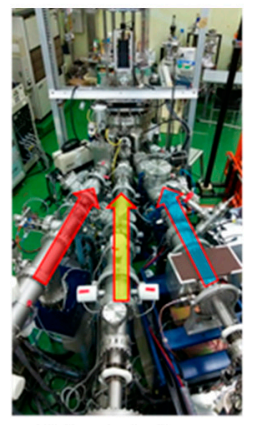

(b)Triple beam
Ion beam from

Tandem

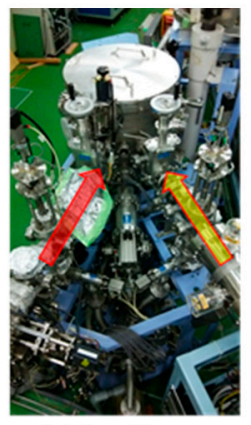

(c)Dual beam

(Single-ended and Implanter)

Single-ended $\longleftrightarrow$

Implanter $\longrightarrow$

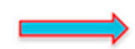

Figure 14. The layout of beam transport lines in the multiple beam irradiation facility and photographs of typical irradiation apparatus described in the text. 
The triple beam irradiation chamber shown in Figure 14b is a powerful tool for fundamental study of structural materials for the future of fusion or fission reactors. The structural materials are exposed with intense neutrons for many years. This causes a degradation of the material's properties through displacement damages, and accumulation of hydrogen and helium gases produced by nuclear reactions. Those synergistic effects can be simulated by triple-beam irradiation; $\mathrm{Fe}^{\mathrm{n}+}$ from the tandem accelerator for displacement damage, $\mathrm{H}^{+}$from the implanter, and $\mathrm{He}^{+}$from the single-ended accelerator for gas accumulation.

An integrated $400 \mathrm{kV}$ analytical electron microscope is connected with the implanter beamline shown in Figure 14d. It was designed to permit in situ observation of the dynamic process of the structural change in materials under simultaneous irradiation of beams from the implanter and a $40 \mathrm{kV}$ inner ion source. This system is combined with electron and X-ray energy analyzers and a computed data acquisition device.

\section{Ion-Microbeam System}

The history of microbeam technology began in the 1970s with the advent of proton microbeams, which were first used for local elemental analysis at mesoscopic length scales [24,25]. Research and development in microbeam technology and applications at TIARA have been ongoing since 1990 . This section describes the present statuses of the heavy-ion and the light-ion microbeam systems at electrostatic accelerators of TIARA.

\subsection{Heavy-Ion Microbeam System}

The heavy-ion microbeam line is connected to the $3 \mathrm{MV}$ tandem accelerator as shown in Figure $14 \mathrm{~A}$, where the various ion species from $\mathrm{H}^{+}$to $\mathrm{Au}^{5+}$ are available. Figure 15 shows the configuration of the beamline comprising a quadrupole doublet lens (DQ2) and three slit systems: a micro-slit (MS), a divergence-defining slit (DS), and a baffle slit (BS). The object distance from MS to the entry of DQ2 is $3.75 \mathrm{~m}$. The image distance from the exit of DQ2 to the target is $0.2 \mathrm{~m}$. A second-order TRANSPORT [26] calculation shows that magnification factors in the $\mathrm{X}$ and $\mathrm{Y}$ directions are, respectively, $1 / 4.6$ and $1 / 28$, in the case of $15 \mathrm{MeV} \mathrm{Ni}^{4+}$ beam [27]. The system has a two-axis electrostatic scanner lying downstream of DQ2 and the scan area is typically $400 \times 400 \mu \mathrm{m}$, in the case of $15 \mathrm{MeV} \mathrm{Ni}^{4+}$ beam. The beam current is usually in the range from $0.1 \mathrm{pA}$ to $10 \mathrm{pA}$, in the case of a diameter of $2 \mu \mathrm{m}$ on the image point.

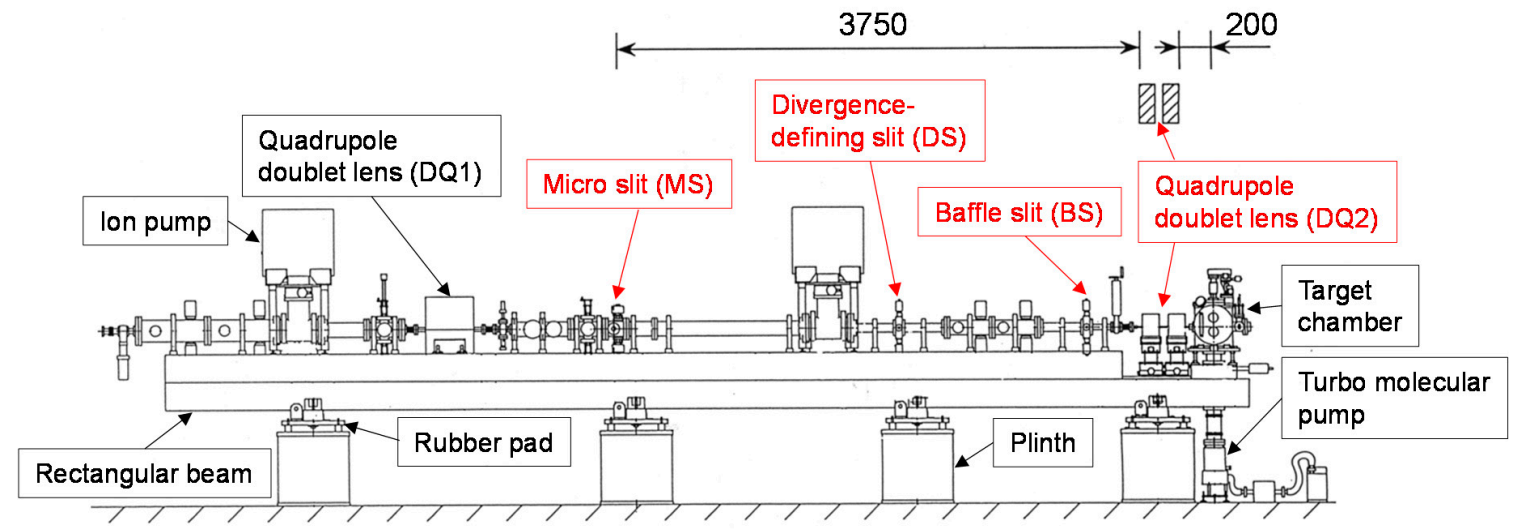

Figure 15. An illustration showing the configuration of the heavy-ion microbeam system.

\subsection{Light-Ion Microbeam System}

The light-ion microbeam line is connected to the $3 \mathrm{MV}$ single-ended accelerator, as shown in Figure $14 \mathrm{~B}$, where $\mathrm{H}^{+}, \mathrm{H}_{2}{ }^{+}, \mathrm{D}^{+}$and $\mathrm{He}^{+}$are available. The optics design is basically the same as the heavy-ion system. The object and the image distances are $8.1 \mathrm{~m}$ and $0.2 \mathrm{~m}$. The magnification 
factors in the $X$ and $Y$ directions are, respectively, $1 / 12$ and 1/60. A two-axis electrostatic scanner lies downstream of a doublet and the scan area is typically $800 \times 800 \mu \mathrm{m}$ in the case of the $3 \mathrm{MeV} \mathrm{H}^{+}$ beam. The beam current is greater than $100 \mathrm{pA}$, in the case of a diameter of $1 \mu \mathrm{m}$ on the image point.

\subsection{Applications}

The MeV-class ion beam has a range of several tens of $\mu \mathrm{m}$, and invokes significant interactions with atoms and molecules in a target. This enables high-sensitivity elemental analysis and highly-efficient microfabrication using the ion microbeam. Hereafter, the examples regarding the application of the ion microbeam are described.

\subsubsection{Single Ion Hit}

A single ion hit system using the heavy-ion microbeam was developed for fundamental studies of the SEE induced by the injection of various heavy particles into semiconductor devices [28]. This system is now used not only for measurement of ion beam induced charge in high-efficient transmission-type particle detectors made of diamond [29,30], but also for implantation of equally-spaced nitrogen-vacancy centers as quantum dots [31]. The single ion hit system basically consists of an electrostatic fast beam switch which controls the irradiation time, and a single ion detection system that verifies a single ion hit and then forms a flip signal for the fast beam switch or trigger signals of the SEE experiment. It is essentially required to detect each single ion injection to a sample with a low noise rate, because the reliability of this system depends on the single ion detection efficiency and the miscounting rate in the measurement system. Figure 16 illustrates a schematic diagram of the single ion hit system. The high voltage of the fast beam switch is normally applied to a deflector electrode for beam-off. When a beam irradiation requirement trigger is formed by a pulser unit, the high voltage falls to $0 \mathrm{~V}$ and ions can go through DS (beam-on). After the preset time passes, a delayed trigger is formed by the pulser and the voltage of the beam switch rises again (beam-off). An annular-type multi-channel plate (MCP) and a constant fraction discriminator (CFD) are used for single ion detection. It is not until a counted number of detection signals reach a preset value that the veto signal is generated by the fast counter.

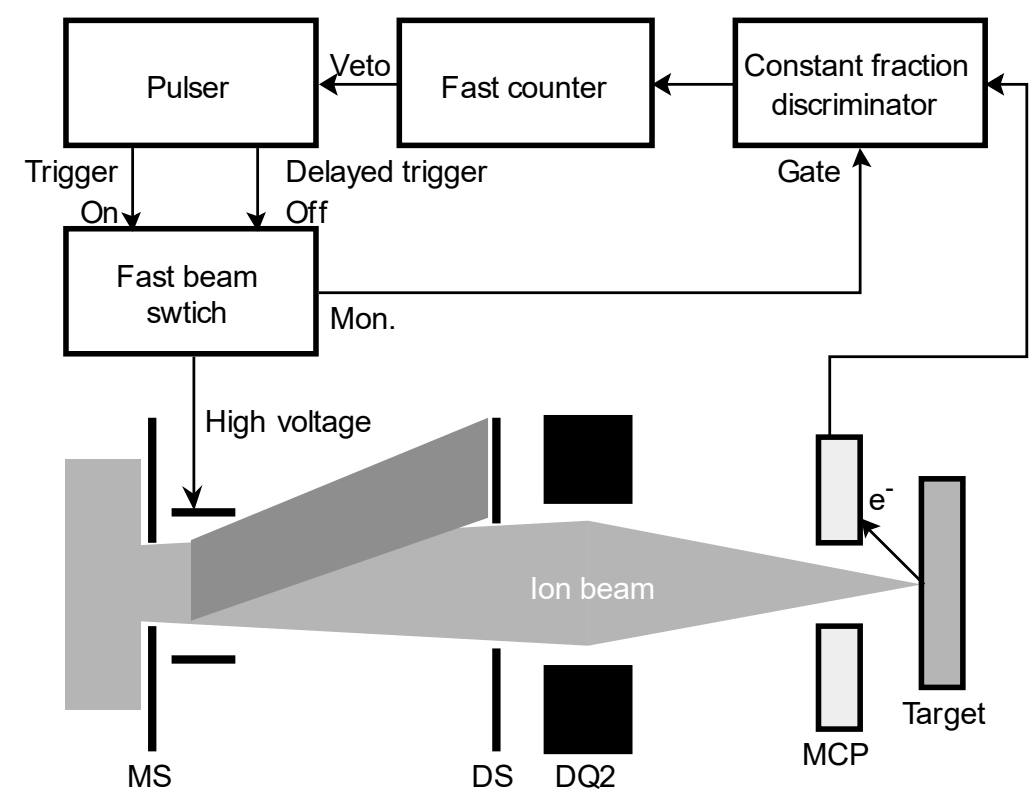

Figure 16. A schematic diagram of the single ion hit system. 


\subsubsection{Micro Particle Induced X/Gamma-ray Emission}

An in-air micro particle induced X-ray emission (micro-PIXE) analyzer using the light-ion microbeam system was initially developed for elemental analysis in small biological samples [32,33]. It consists of the light-ion microbeam line, a beam position control, and several X-ray detectors. The microbeam always scans on an interesting region of a target at a rate of several seconds per scan during measurement. The energy of X-ray photons and the beam position are simultaneously recorded event by event and stored in list mode. Therefore, the elemental maps can be provided as a function of time. The condition of the target in a mirror is observed with a microscope and a charge-coupled device (CCD) camera during beam irradiation. The cross-sectional view of the system is shown in Figure 17. The microbeam passes through a 5 - $\mu \mathrm{m}$-thick polyethylene terephthalate membrane and irradiates the target in the air. The transmitted beam is stopped in a beam dump made of glassy carbon. The beam spot size is approximately $1 \mu \mathrm{m}$ in diameter on the target plane and the spreading of the beam after passing through the membrane is approximately $0.2 \mu \mathrm{m}$. The following are examples of micro-PIXE or micro particle induced gamma-ray emission (micro-PIGE) analysis.

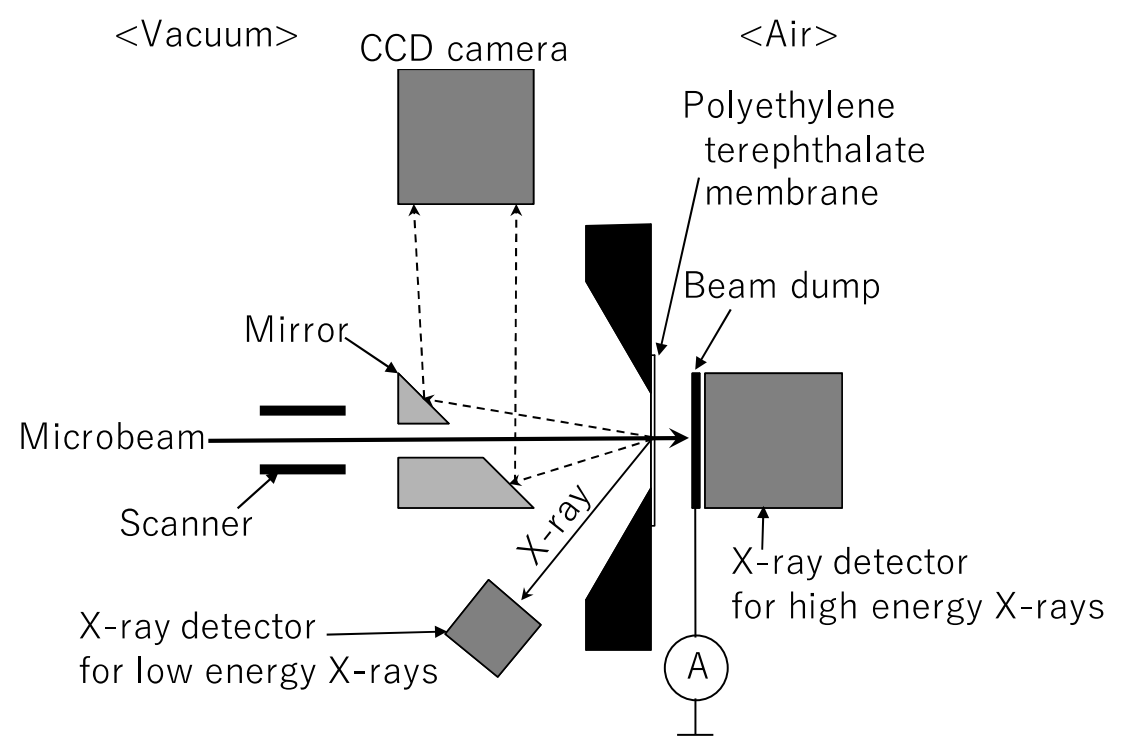

Figure 17. A cross-sectional view of the in-air micro-PIXE (particle induced X-ray emission) system.

Diagnosis of patients experiencing inhalation of asbestos is usually performed by confirming the existence of a partial hypertrophy and fibrotic lung with radiography and tomography. However, it is impossible to detect microscopic asbestos by those methods. Micro-PIXE analysis can obtain information on the quantity and the kind of the asbestos from several milligrams of pulmonary tissue extracted from lung cancer patients [34].

Li-ion batteries (LIB) are one of the rechargeable batteries where $\mathrm{Li}$ ions move back and forth between the negative and the positive electrodes during charging and discharging. The performance of LIB depends on the mobility of $\mathrm{Li}$ ions in its electrode. The distribution of $\mathrm{Li}$ in the positive electrode is measured using micro-PIGE analysis. It appears that micro-PIGE analysis can contribute to the optimization of the composition of the electrode material since it can measure Li distribution quantitatively with high spatial resolution [35].

\subsubsection{Proton Beam Writing}

Proton beam writing (PBW) is a direct writing technique for the fabrication of micro- or nanometer-sized structures on polymer film by chemical etching after irradiation [36]. The PBW system consists of the light-ion microbeam line, a beam position control, and a beam switch. Figure 18 presents 
a schematic diagram of the PBW system. Following pre-populated point data, a scanner can draw arbitrary shapes on the target, and a beam switch blanks the beam after drawing. The beam current is approximately $10 \mathrm{pA}$ in the case of polymer film as a target. Since the scattering of protons with energy on the order of $\mathrm{MeV}$ is suppressed, compared with electrons, the PBW is a promising technique for the micro-machining of structures with a high aspect ratio [37]. Moreover, three-dimensional structures, such as an arch, can be fabricated by changing the beam energy and range [38].

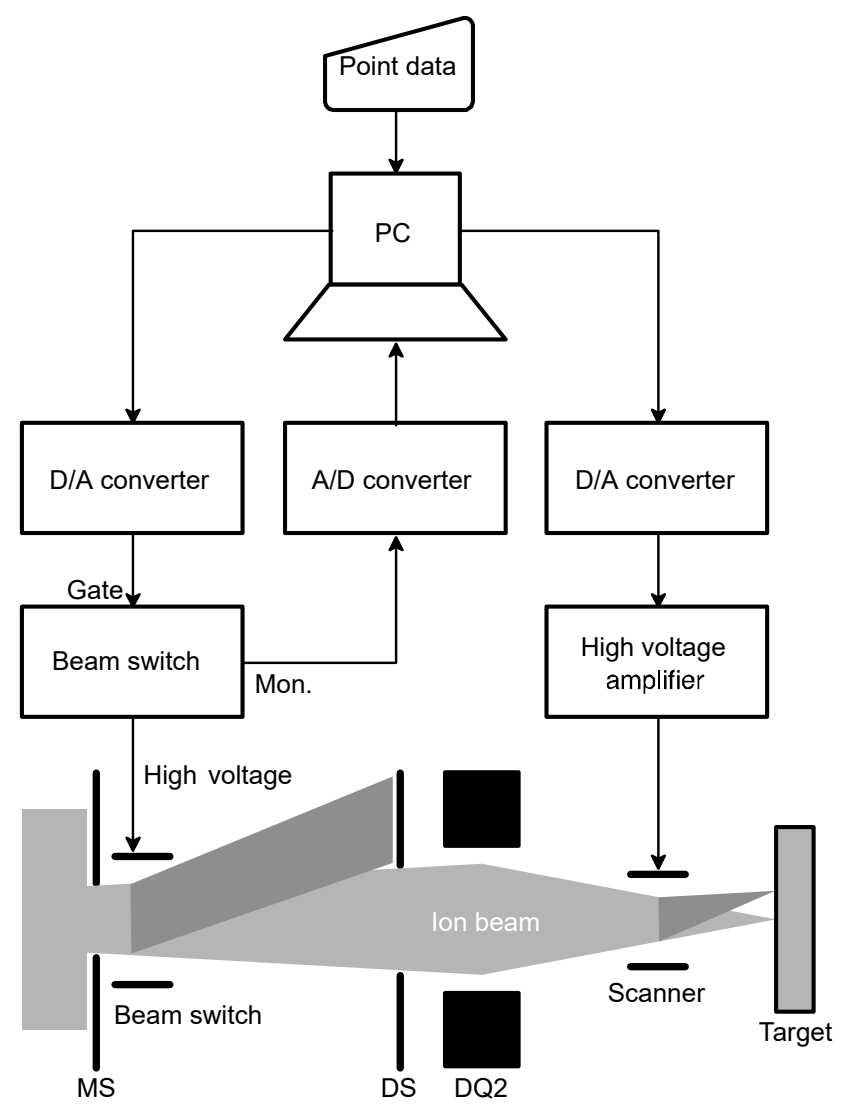

Figure 18. A schematic diagram of the PBW (proton beam writing) system.

Author Contributions: The structure of the article was considered by all authors. Watalu Yokota wrote Sections 1 and 2, Satoshi Kurashima Sections 3-5, Yuichi Saitoh Section 6, Takahiro Satoh Section 7.

Conflicts of Interest: The authors declare no conflict of interest.

\section{References}

1. Arakawa, K.; Nakamura, Y.; Yokota, W.; Fukuda, M.; Nara, N.; Agematsu, T.; Okumura, S.; Ishibori, I.; Karasawa, T.; Tanaka, R.; et al. Construction and first year's operation of the JAERI AVF cyclotron. In Proceedings of the 13th International Conference on Cyclotrons and Their Applications, Vancouver, BC, Canada, 6-12 July 1992; Dutto, G., Craddock, M.K., Eds.; World Scientific: Singapore, 1992; pp. 119-122.

2. Saitoh, Y.; Tajima, S.; Takada, I.; Mizuhashi, K.; Uno, S.; Ohkoshi, K.; Ishii, Y.; Kamiya, T.; Yotumoto, K.; Tanaka, R.; et al. TIARA electrostatic accelerators for multiple ion beam application. Nucl. Instrum. Methods Phys. Res. B 1994, 89, 23-26. [CrossRef]

3. Koivisto, H.; Arje, J.; Nurmia, M. Metal ions from the volatile compounds method for the production of metal ion beams. Rev. Sci. Instrum. 1998, 69, 785-787. [CrossRef]

4. Yoshida, K.; Nara, T.; Saitoh, Y.; Yokota, W. Stability study of all-permanent-magnet electron cyclotron resonance ion source. Rev. Sci. Instrum. 2010, 81, 02A312. [CrossRef] [PubMed] 
5. Kurashima, S.; Miyawaki, N.; Okumura, S.; Ishibori, I.; Nara, T.; Agematsu, T.; Yoshida, K.; Yokota, W.; Nakamura, Y.; Arakawa, K.; et al. Single-turn extraction from a K110 AVF cyclotron by flat-top acceleration. Rev. Sci. Instrum. 2009, 80, 033302. [CrossRef] [PubMed]

6. Miyawaki, N.; Fukuda, M.; Kurashima, S.; Kashiwagi, H.; Okumura, S.; Arakawa, K.; Kamiya, T. Evaluation of phase bunching in the central region of a cyclotron by a radial probe with a plastic scintillator. Nucl. Instrum. Methods Phys. Res. A 2014, 767, 372-378. [CrossRef]

7. Kashiwagi, H.; Miyawaki, N.; Kurashima, S.; Okumura, S. A transverse emittance and acceptance measurement system in a low-energy beam transport line. Rev. Sci. Instrum. 2014, 85, 02A735. [CrossRef] [PubMed]

8. Okumura, S.; Arakawa, K.; Fukuda, M.; Nakamura, Y.; Yokota, W.; Ishimoto, T.; Kurashima, S.; Ishibori, I.; Nara, T.; Agematsu, T.; et al. Magnetic field stabilization by temperature control of an azimuthally varying field cyclotron magnet. Rev. Sci. Instrum. 2005, 76, 033301. [CrossRef]

9. Kurashima, S.; Miyawaki, N.; Kashiwagi, H.; Okumura, S.; Taguchi, M.; Fukuda, M. Enhancement of beam pulse controllability for a single-pulse formation system of a cyclotron. Rev. Sci. Instrum. 2015, 86, 073311. [CrossRef] [PubMed]

10. Kurashima, S.; Yuyama, T.; Miyawaki, N.; Kashiwagi, H.; Okumura, S.; Fukuda, M. Useful technique for analysis and control of the acceleration beam phase in the azimuthally varying field cyclotron. Rev. Sci. Instrum. 2010, 81, 033306. [CrossRef] [PubMed]

11. Masuda, A.; Matsumoto, T.; Harano, H.; Tanimura, Y.; Shikaze, Y.; Yoshitomi, H.; Nishino, S.; Kurashima, S.; Hagiwara, M.; Unno, Y.; et al. Time-of-Flight Measurements for Low-Energy Components of 45-MeV Quasi-Monoenergetic High-Energy Neutron Field from ${ }^{7} \operatorname{Li}(\mathrm{p}, \mathrm{n})$ Reaction. IEEE Trans. Nucl. Sci. 2015, 62, 1295-1300. [CrossRef]

12. McMahan, M.A. The Berkeley Accelerator Space Effects (BASE) Facility-A new mission for the 88-Inch Cyclotron at LBNL. Nucl. Instrum. Methods Phys. Res. B 2005, 241, 409-413. [CrossRef]

13. Ziegler, J.F. Computer Code SRIM-2013. Available online: http://www.srim.org/ (accessed on 28 December 2016).

14. Yuri, Y.; Ishizaka, T.; Yuyama, T.; Ishibori, I.; Okumura, S.; Yoshida, K. Formation of a large-area uniform ion beam using multipole magnets in the TIARA cyclotron. Nucl. Instrum. Methods Phys. Res. A 2011, 642, 10-17. [CrossRef]

15. Funayama, T.; Wada, S.; Yokota, Y.; Fukamoto, K.; Sakashita, T.; Taguchi, M.; Kakizaki, T.; Hamada, N.; Suzuki, M.; Furusawa, Y.; et al. Heavy-Ion Microbeam System at JAEA-Takasaki for Microbeam Biology. J. Radiat. Res. 2008, 49, 71-82. [CrossRef] [PubMed]

16. Oikawa, M.; Satoh, T.; Sakai, T.; Miyawaki, N.; Kashiwagi, H.; Kurashima, S.; Okumura, S.; Fukuda, M.; Yokota, W.; Kamiya, T. Focusing high-energy heavy ion microbeam system at the JAEA AVF cyclotron. Nucl. Instrum. Methods Phys. Res. B 2007, 260, 85-90. [CrossRef]

17. Kurashima, S.; Yoshida, K.; Oikawa, M.; Satoh, T.; Miyawaki, N.; Yuyama, T.; Okumura, S.; Kashiwagi, H.; Ishibori, I.; Nara, T.; et al. Quick change of ion species of heavy-ion microbeam by cocktail beam acceleration technique with the JAEA AVF cyclotron. Nucl. Instrum. Methods Phys. Res. B 2009, 267, 2024-2027. [CrossRef]

18. Saitoh, Y.; Chiba, A.; Narumi, K. Transmission of cluster ions through a tandem accelerator of several stripper gases. Rev. Sci. Instrum. 2009, 80, 106104. [CrossRef] [PubMed]

19. Saitoh, Y.; Mizuhashi, K.; Tajima, S. Acceleration of cluster and molecular ions by TIARA 3 MV tandem accelerator. Nucl. Instrum. Methods Phys. Res. A 2000, 452, 61-66. [CrossRef]

20. Chiba, A.; Usui, A.; Yamada, K. Novel Approach to Intensification and Stabilization of Negative Fullerene Ion Beam Using a Cesium Sputter Type Ion Source; JAEA-Review 2014-050; Japan Atomic Energy Agency: Ibaraki-ken, Japan, 2015; p. 169. Available online: http:/ /jolissrch-inter.tokai-sc.jaea.go.jp/pdfdata/JAEA-Review-2014050.pdf (accessed on 28 December 2016).

21. Middleton, R. A versatile high intensity negative ion source. Nucl. Instrum. Methods Phys. Res. B 1983, 214, 139-150. [CrossRef]

22. Girinius, R.; Anderson, L.W. Collisions, $\mathrm{He}^{+}$ions with a Rb vapor target. Nucl. Instrum. Methods 1976, 137, 373-378. [CrossRef]

23. Saitoh, Y.; Ohkoshi, K.; Arakawa, K. Development of 13 GHz Compact Electron Cyclotron Resonance Ion Source. Rev. Sci. Instrum. 2004, 75, 1502-1505. [CrossRef] 
24. Cookson, J.A. The production and use of a nuclear microprobe of ions at MeV energies. Nucl. Instrum. Methods 1979, 165, 477-508. [CrossRef]

25. Legge, G.J.F. A history of ion microbeams. Nucl. Instrum. Methods Phys. Res. B 1997, 130, 9-19. [CrossRef]

26. Brown, K.L.; Carey, D.C.; Iselin, C.; Rothacker, F. Transport, a Computer Program for Designing Charged Particle Beam Transport Systems; Yellow Report CERN 80-04; CERN: Geneva, Switzerland, 1980.

27. Tajima, S.; Takada, I.; Mizuhashi, K.; Uno, S.; Okoshi, K.; Nakajima, Y.; Saito, Y.; Ishii, Y.; Kamiya, T. TIARA Electrostatic Accelerator Facility; JAERI-Tech-96-029; Japan Atomic Energy Research Institute: Ibaraki-ken, Japan, 1996.

28. Price, W.E.; Coss, J.R. Single event phenomena: A summary. Nucl. Instrum. Methods Phys. Res. B 1989, 40, 1306-1309. [CrossRef]

29. Grilj, V.; Skukan, N.; Pomorski, M.; Kada, W.; Iwamoto, N.; Kamiya, T.; Ohshima, T.; Jakšić, M. An ultra-thin diamond membrane as a transmission particle detector and vacuum window for external microbeams. Appl. Phys. Lett. 2013, 103, 243106. [CrossRef]

30. Grilj, V.; Skukan, N.; Jakšić, M.; Kada, W.; Kamiya, T. Irradiation of thin diamond detectors and radiation hardness tests using MeV protons. Nucl. Instrum. Methods Phys. Res. B 2013, 306, 191-194. [CrossRef]

31. Yamamoto, T.; Onoda, S.; Ohshima, T.; Teraji, T.; Watanabe, K.; Koizumi, S.; Umeda, T.; McGuinness, L.P.; Müller, C.; Naydenov, B.; et al. Isotopic identification of engineered nitrogen-vacancy spin qubits in ultrapure diamond. Phys. Rev. B 2014, 90, 81117. [CrossRef]

32. Kamiya, T.; Suda, T.; Tanaka, R. Sub-micron microbeam apparatus for high resolution materials analyses. Nucl. Instrum. Methods Phys. Res. B 1996, 118, 447-450. [CrossRef]

33. Ishii, K.; Sugimoto, A.; Tanaka, A.; Satoh, T.; Matsuyama, S.; Yamazaki, H.; Akama, C.; Amartivan, T.; Endoh, H.; Oishi, Y.; et al. Elemental analysis of cellular samples by in-air micro-PIXE. Nucl. Instrum. Methods Phys. Res. B 2001, 181, 448-453. [CrossRef]

34. Shimizu, Y.; Dobashi, K.; Kusakabe, T.; Nagamine, T.; Oikawa, M.; Satoh, T.; Haga, J.; Ishii, Y.; Ohkubo, T.; Kamiya, T.; et al. In-air micro-particle induced X-ray emission analysis of asbestos and metals in lung tissue. Int. J. Immunopathol. Pharmacol. 2008, 21, 567-576. [CrossRef] [PubMed]

35. Mima, K.; Gonzalez-Arrabal, R.; Azuma, H.; Yamazaki, A.; Okuda, C.; Ukyo, Y.; Sawada, H.; Fujita, K.; Kato, Y.; Perlado, J.M.; et al. Li distribution characterization in Li-ion batteries positive electrodes containing LixNi0.8Co0.15A10.05O2 secondary particles (0.75 $\leq \mathrm{x} \leq 1.0)$. Nucl. Instrum. Methods Phys. Res. B 2012, 290, 79-84. [CrossRef]

36. Van Kan, J.A.; Bettiol, A.A.; Watt, F. Proton beam writing of three-dimensional nanostructures in hydrogen silsesquioxane. Nano Lett. 2006, 6, 579-582. [CrossRef] [PubMed]

37. Van Kan, J.A.; Shao, P.G.; Ansari, K.; Bettiol, A.A.; Osipowicz, T.; Watt, F. Proton beam writing: A tool for high-aspect ratio mask production. Microsyst. Technol. 2007, 13, 431-434. [CrossRef]

38. Furuta, Y.; Uchiya, N.; Nishikawa, H.; Haga, J.; Sato, T.; Oikawa, M.; Ishii, Y.; Kamiya, T. Fabrication of three-dimensional structures of resist by proton beam writing. J. Vac. Sci. Technol. B 2007, 25, 2171-2174. [CrossRef]

(c) 2017 by the authors. Licensee MDPI, Basel, Switzerland. This article is an open access article distributed under the terms and conditions of the Creative Commons Attribution (CC BY) license (http:/ / creativecommons.org/licenses/by/4.0/). 